\title{
LOYALITAS PELANGGAN DITINJAU DARI PELAYANAN, CITRA DAN KEPUASAN (STUDI PADA KLINIK PRATAMA POLRES WONOGIRI)
}

\author{
Sutrisno Widodo ${ }^{1}$, Istiatin ${ }^{2}$, Djumali ${ }^{3}$ \\ Fakultas Ekonomi Universitas Islam Batik Surakarta \\ Jl. KH. Agus Salim No. 10 Surakarta

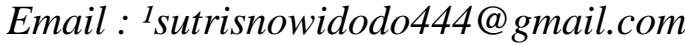

\begin{abstract}
This study intends to understand the influence of services, image and satisfaction with the loyalty of patients at the Clinic Primary wonogiri district police. The population of this study were all patients whose outpatient using Indonesia Cards Primary Health Clinic Police Wonogiri. Methods this study included descriptive quantitative research by spreading the questionnaire. The sampling method is accidental sampling is carried by taking sample at the time of the researchers selects or encounter respondents treadment. The number of samples taken 100 respondents of the number of patients at the Clinic Primary Wonogiri district police who visited more than 3 times. Test the validity of the instrument wear product moment classical assumption test, multiple linear regression analisis, $t$ test, $F$ test and the coefficient of determination. The study states that the services, image and satisfaction simultaneously significant effect on patient loyalty Primary Clinik Police wonogiri. Services are not positive and not significant to the Primary Clinic patient loyalty Wonogiri district police. Clinic image positive and significant impact on patient loyalty Primary Clinic Police Wonogiri. Satisfaction positive and signifikan impact on patient loyalty Primary Clinic Police Wonogiri.
\end{abstract}

Keywords: loyalty, service, image, satisfaction, clinic

\section{PENDAHULUAN}

Perkembangan ilmu kesehatan berakibat pengetahuan dimata masyarakat naik, sehingga dalam memilih fasilitas pelayanan kesehatan lebih spesifik. Pemilihan fasilitas kesehatan biasanya dicari melalui berbagai media internet yang kemudian dibandingkan untuk mengambil keputusan dimana yang akan menjadi layanan kesehatan pilihan. Indikator layanan yang sangat penting dalam layanan kesehatan pada dasarnya yang dibutuhkan adalah sehat jasmani dan rohani sehingga dalam beraktifitas kegiatannya akan menjadi lebih baik maka dibutuhkan akan pelayanan kesehatan yang optimal. Pemenuhan kebutuhan dalam mencapai kepuasan pelanggan maka keberhasilan terutama dalam hal kesehatan akan menguatkan loyalitas pelanggan.

Loyalitas pasien secara signifikan berhubungan positif dengan pelayanan keseluruhan yang ditunjukkan melalui penggunaan kembali Rumah Sakit untuk pengobatan yang sama maupun berbeda, dan merekomendasikan kepada orang lain (Abdurrouf \& Puspitasari, 2017).

Kesetiaan atau loyalitas merupakan sesuatu yang memiliki manfaat besar terbentuk karena kepuasan dan pelayanan (Otani, Herrmann, \& Kurz, 2010). Pelayanan memiliki pengaruh positif terhadap kepuasan yang menimbulkan pasien kembali berkunjung ke klinik daa menyarankan pada keluarga dan teman lainnya. Pelayanan dipengaruhi oleh persepsi pasien terhadap citra Poliklinik (Hidajahningtyas, Sularso, \& Suroso, 2013).

Dalam perusahaan citra sangatlah penting yang merupakan suatu harta atau aset yang tak berwujud. Apabila citra baik maka kepuasan, kualitas layanan, dan loyalitas pelanggan bertambah sehingga muncul niat akan kembali dalam pembelian. Bahwa citra yang baik akan 
meningkatkan loyalitas pelanggan (Nursaidah, 2017). Sementara citra yang buruk akan mengakibatkan reputasi suatu perusahaan menurun bahkan memperburuk.

Perilaku dan sikap pasien akan berdampak pada citra rumah sakit sehingga pemahaman hubungan keduanya mempengaruhi keinginan pasien terhadap citra klinik. Kesetiaan pelanggan merupakan kunci sukses bagi pencitraan rumah sakit. Menurut Wu (2011) bahwa ada fungsi hubungan antara citra merek rumah sakit dengan hubungannya dengan keharmonisan suatu pelanggan.

Menurut pendapat (Qomariah, 2012) bahwa kepuasan pelanggan merupakan bagian yang terpenting dari suatu loyalitas pelanggan, sehingga dapat menciptakan peningkatan loyalitas pelanggan. Persepsi atau kesan dari kepuasan atas harapan dan kinerja merupakan bagian dari kepuasan pelanggan, apabila kinerja sesuai harapan pelanggan maka akan timbul kepuasan dan merasa senang. Hal ini diperkuat oleh temuan Ma'ruf (2016) bahwa layanan yang prima akan meningkatkan kepuasan pelanggan rumah sakit.

Peningkatan pelayanan kesehatan terhadap pelanggan akan meningkatkan sumber pendapatan bagi rumah sakit maupun klinik. Bentuk jasa layanan kesehatan yang perlu diperhatikan dalam menciptakan kepuasan dan loyalitas pelanggan perlu adanya indikator dari petugas kesehatan. Bentuk jasa layanan kesehatan meliputi mampu menangani penyakit dengan cepat dan akurat, dengan cara keramahan dan kesigapan dan kecepatan para tenaga medis, dan pegawai lainya. Dengan kepuasan akan berdampak pada banyaknya kunjungan sehingga diharapkan terbentuk kepuasan dan loyalitas.

Berdasarkan data jumlah kunjungan rawat jalan di Klinik Pratama Polres Wonogiri dari tahun 2017 sebanyak 2526, tahun 2018 sebanyak 3349 jika dibandingkan data pada tahun 2019 sebanyak 2974 memiliki rata-rata kunjungan pasien rawat jalan mengalami penurunan. (Rekapitulasi Data Klinik Polres Wonogiri Tahun 2019). Kemungkinan penurunan dari kunjungan pasien adalah adanya kesadaran akan pola hidup sehat yang sudah dijaga, tetapi kemungkinan disebabkan beberapa hal masalah, seperti citra klinik yang kurang baik, lingkungan yang dianggap kurang nyaman, waktu tunggu tenaga medis yang terlalu lama, pelayanan tenaga medis yang kurang maksimal, serta pelayanan pengobatan yang belum memuaskan.

Sebagaimana diketahui Klinik Pratama Polres Wonogiri merupakan klinik di bawah satuan Polres Wonogiri, sebelum menjadi klinik Pratama, pusat layanan kesehatan semula hanya melayani anggota Polri dan keluarganya dan berstandar poliklinik. Dalam perkembangan lambat laun menjadi Klinik Pratama Polres Wonogiri dengan dukungan dari Biddokkes Polda Jateng sehingga sekarang klinik melayani pelayanan masyarakat umum secara Cuma-Cuma atau tanpa dipungut biaya. Disamping pelayanan kesehatan dan pengobatan rawat jalan terhadap anggota Polri, PNS, keluarga dan masyarakat umum serta kesehatan tahanan, pelayanan kesehatan lainya meliputi konsultasi kesehatan, chek-up, pemeriksaan gigi, home visit, rikkes berkala dan tugas pelayanan dokpol.

Berdasarkan latar belakang diatas penulis memfokuskan pada pelayanan rawat jalan di Klinik Pratama Polres Wonogiri dengan pasien yang berkunjung menggunakan Kartu Indonesia Sehat.

\section{LANDASAN TEORI}

\section{Loyalitas}

Secara literal atau harfiah kata "Loyalitas" diinterpretasikan sebagai kesetiaan terhadap suatu objek. Pengertian loyalitas sebagai komitmen pelanggan secara mendalam tetap bertahan dan konsisten untuk berlangganan berulang yang menyebabkan berpotensi perubahan prilaku (Hurriyati, 2005, p. 35). 
Loyalitas adalah perilaku konsumen yang berkomitmen bertahan dalam memperoleh ketentuan untuk tetap merekomendasikan dalam pembelian produk secara berulang-ulang.

\section{Mutu Pelayanan}

Menurut Muninjaya, (2004: 19) bahwa Mutu merupakan sesuatu diinginkan atau ditetapkan oleh pelanggan. Mutu memiliki sifat yang komplek dari dimensi dan segi, sehingga maknanya didasarkan pada sifat individu, absolutis dan sosialis (Mukti, 2007, p. 9).

Mutu didefinisikan sebagai karakteristik suatu produk secara langsung. Sedangkan menurut Kotler (2002, p. 67) bahwasanya kualitas yaitu totalitas dari ciri dan tabiat yang berdampak pada kapabilitas untuk memenuhi pernyataan tersirat.

Standar profesi layanan kesehatan difasilitas kesehatan terutama rumah sakit dan klinik atau puskesmas diberikan secara efektif, wajar, efisien aman dan memuaskan berdasarkan mutu pelayanan kesehatan untuk mencapai kesempurnaan derajat kesehatan (Satianegara, 2009, p. 106). Bahwa mutu pelayanan pelayanan merupakan ukuran terhadap produk atau jasa dari pandangan dimensi, sifat, bentuk, penampilan, performa yang memenuhi harapan kebutuhan, kenyamanan dan keamanan pelanggan.

\section{Citra}

Peter \& Olson (2002, p. 248-249) menyebutkan definisi citra bahwa sesuatu terpikirkan konsumen terhadap produk termasuk persepsi atas dasar reaksi Indra kelima terkait pada perusahaan. Sutisna (2001, p. 33) berpendapat bahwa citra adalah alat keyakinan tentang pesan yang dapat dimiliki terhadap obyek yang mempunyai tujuan utama untuk mencapai prestasi yang terbaik pada relations publik.

Bahwa citra merupakan abstrak (intangible) sehingga tidak dapat diukur tetapi dapat diwujudkan dan dirasakan secara baik maupun buruk. Berdasarkan uraian di atas menurut keterangan penulis maka pengertiancitra merupakan gambaran suatu kesan yang timbul dari indra manusia bersifat abstrak dapat diwujudkan melalui penilaian dan dirasakan baik maupun buruk.

\section{Kepuasan}

Kepuasan diuraikan tingkat perasaan yang menyamakan hasil kinerja dirasakan terhadap harapan pelanggan dan kepuasan pelanggan bertujuan pelayanan prima (Daryanto, 2014, p. 127). Kepuasan pasien ditimbulkan akibat dari perasaan pasien membandingkan antara kinerja kesehatan yang didapatkannya untuk mencapai pengharapan kepuasan (Pohan, 2006). Kotler (2007, p. 175) bahwa kepuasan menerangkan perasaan suka atau kecewa akibat perbandingan kinerja pelayanan yang diapresiasikan hasil produk terhadap ekspektasi mereka.

\section{METODE PENELITIAN}

\section{Lokasi dan Waktu Penelitian}

Penelitian telah dilakukan pada Klinik Pratama Polres Wonogiri yang beralamat di J1. Jendral Sudirman No. 153 Giritirto Wonogiri, Jawa Tengah. Waktu penelitian dilakukan selama bulan Desember 2019 - Januari 2020.

\section{Sampel dan Populasi}

Populasi yaitu semua pasien yang berobat rawat jalan di Klinik Pratama Polres Wonogiri. Sampel secara accidental sampling dengan mengambil dari populasi berdasarkan ketentuan dari peneliti yaitu pada saat peneliti memilih atau menjumpai responden yang berobat dengan jumlah 
sampel 100 responden di klinik Pratama Polres Wonogiri. Dengan kriteria sampel yaitu pasien yang telah berkunjung ke klinik lebih dari 3 kali dan berkemampuan komunikasi yang baik.

\section{Sumber dan Jenis Data}

Metode dipakai peneliti termasuk jenis penelitian kuantitatif deskriptif mengenai pelayanan, citra, kepuasan dan loyalitas terhadap Klinik Pratama Polres Wonogiri. Dengan sumber data sekunder dan primer.

\section{Tehnik pengumpulan data} pustaka.

Untuk penelitian memakai observasi, wawancara, dokumentasi, kuisionir, pencarian

\section{Variabel Penelitian}

Variabel penelitian meliputi variabel dependendan dan Independen. Variabel Dependen penelitian ialah Loyalitas pelanggan. Sedangkan variabel Independen (bebas) yang menjadi sebab adalah pelayanan, citra dan kepuasan.

\section{Uji instrumen}

Peneliti menggunakan aplikasi software IBM SPSS Statistics 25 untuk uji Instrumen. Pada uji validitas memakai metode product moment correlation, dengan seluruh jumlah pertanyaan pada kuesioner, dilakukan pada sampel terdahulu sebanyak 20 responden. Sedangkan uji reliabilitas dengan metode Alpha Cronbach. Nilai hasil koefisien $<0,6$ berarti nilai tidak reliabel (Suharsimi, 2013).

Dari keterangan Tabel 1 pada pengujian SPSS dapat diketahui bahwa variabel validitas pernyataan nilai rhitung lebih besar rtabel, maksemua pernyataan dinyatakan valid dan tidak ada pertanyaan yang dihapus. Sedangkan pada uji reliabilitas diketahui Cornbach's Alpha > 0,60 sehingga instrumen penelitian terhadap pelayanan, citra, kepuasan dan loyalitas berarti reliabel.

\section{HASIL PENELITIAN DAN PEMBAHASAN}

Hasil data berdasarkan karakteristik identitas responden terdiri dari pekerjaan, usia, pekerjaan dan jenis kelamin, sehingga dapat dirangkum dalam tabel berikut ini. Dari data pasien berobat di klinik Pratama Polres Wonogiri terbanyak laki-laki 57 orang, perempuan 47 orang. Usia pada umur lebih dari 50 tahun sebanyak 36 orang. Mayoritas pendidikan terakhir responden yang berkunjung ke Klinik Pratama Polres Wonogiri adalah lulusan SMA/SMK sederajat dengan jumlah 57 orang. Sedangkan dilihat dari jenis pekerjaan responden mayoritas adalah Polri/TNI yaitu sebesar 43 orang.

\section{Uji Asumsi Klasik}

Jika nilai estimasi yang diperoleh melalui rumus regresi telah memenuhi asumsi-asumsi regresi (Pawenang \& Kustiyah, 2011, p. 79).

Uji Normalitas yang digunakan kolmogrrov-Smirnov-tes. bilamana hasil normalmaka nilai signifikannya lebih dari 0.05 , jika kurang maka uji tersebut tidak memenuhi asumsi normalitas. (Ghozali, 2013, p. 160).

Tabel 3 Hasil Uji Normalitas

\begin{tabular}{|c|c|c|}
\hline Asymp. Sig. (2-tailed) & Batas & Indikasi \\
\hline 0.068 & 0.05 & Normal \\
\hline
\end{tabular}

Sumber data primer 2020 
Berdasarkan hasil Tabel 3 pengujian dengan SPSS menunjukkan bahwa uji normalitas nilai Asymp. Sig. 0,068 > 0.05 model regresi sudah terpenuhi.

Uji Multikolonieritas dengan melihat nilai VIF (Variance Inflation Factor) pada model regresi. Jika besar VIF < 10, atau tollerance $>0.10$ maka tidak terjadi multikolonieritas (Ghozali, 2013, p. 105). Didapatkan hasil uji multikolonieritas dalam tabel berikut:

Tabel 4 Hasil Multikolonieritas

\begin{tabular}{|c|c|c|c|c|}
\hline No. & Variabel & Tollerance & VIF & Keterangan \\
\hline 1 & Pelayanan & 0.485 & 2.062 & $\begin{array}{c}\text { Tidak terjadi } \\
\text { Multikolonieritas }\end{array}$ \\
\hline 2 & Citra & 0.352 & 2.845 & $\begin{array}{c}\text { Tidak terjadi } \\
\text { Multikolonieritas }\end{array}$ \\
\hline 3 & Kepuasan & 0.361 & 2.771 & $\begin{array}{c}\text { Tidak terjadi } \\
\text { Multikolonieritas }\end{array}$ \\
\hline
\end{tabular}

Sumber data primer 2020

Hasil tabel 4. pada pengujian SPSS menunjukkan bahwa uji Multikolonieritas nilai Tolerance untuk variabel Pelayanan 0,485 Citra Klinik 0,352 dan Kepuasan 0,361 > 0,10 sementara nilai VIF (Variance Inflation Factor) Pelayanan 2,0062 Citra 2,845 Kepuasan 2,771 < 10 maka tidak ada gejala multikolonieritas dalam model regresi.

Uji Heterodasitas dengan metode Glejser pada SPSS untuk mengetahui model regresi terjadinya tidaksamaan varian residual.hasil dari metode glejser pada pengujian SPSS diketahui nilai signifikan variabel pelayanan 0.165 , citra 0,243 dan kepuasan 0,819 lebih besar 0,05 berarti disimpulkan tidak ada Heteroskedastisitas dalam model regresi.

\section{Regresi Linear Berganda}

Analisis regresi linier dipakai untuk mengetahui pengaruh keadaan tingkat naik turunnya variabel dependen, sebagai faktor prediktor variabel independen bila lebih dua dapat dinaikkan atau diturunkan nilainya (Pawenang \& Kustiyah, 2011, p. 59). Analisis dalam penelitian yang digunakan meliputi pelayanan (X1), citra (X2), kepuasan (X3) dan loyalitas pasien (Y). Secara umum berikut rumusnya:

Hasilnya:

$$
\mathrm{Y}=\alpha+\mathrm{b} 1 \mathrm{X} 1+\mathrm{b} 2 \mathrm{X} 2+\mathrm{b} 3 \mathrm{X} 3+\ldots \ldots+\mathrm{bnXn+e}
$$

$$
\mathrm{Y}=(0.321)-0.129 \mathrm{X} 1+0.379 \mathrm{X} 2+0.984 \mathrm{X} 3+\mathrm{e}
$$

Tabel 5 regrei linear Berganda

\begin{tabular}{|l|c|c|c|}
\hline \multicolumn{1}{|c|}{ Variabel } & KoefisienRegresi & thitung & Sig. \\
\hline Konstanta & 0,321 & & \\
\hline X1 & $-0,129$ & $-1,131$ & 0,261 \\
\hline X2 & 0,379 & 3,356 & 0,001 \\
\hline X3 & 0,984 & 5,581 & 0,000 \\
\hline Fhitung & 56,610 & 0,000 \\
R Square & 0,639 & \\
\hline
\end{tabular}

Sumber data primer 2020 

bahwa:

Penjelasan regresi diatas bahwa Interpretasi pada Tabel 5 regresi diatas disimpulkan

Nilai (a) semua variabel Independen nilai 0 maka variabel (Beta) 0,321. Nilai koefisien pelayanan variabel X1 -0,129 dan bertanda negatif, menunjukkan bahwa pelayanan berlawanan haluan dengan loyalitas. Mengenai hal ini berarti setiap ada kenaikan satu satuan variabel Beta (Y) turun 0,129 asumsi variabel Independen lainya idak berubah atau tetap.

Nilai koefisien citra sebesar 0,379 dan positif. bahwa citra mempunyai haluan sejalur dengan loyalitas. Mengenai perihal ini berarti bila citra naik maka variabel Beta (Y) naik 0.379 dengan asumsi variabel independen lainya tidak berubah atau tetap.

Nilai koefisien kepuasan sebesar 0,984 dan bertanda positif, ini menunjukkan bahwa kepuasan mempunyai haluan sejalur dengan loyalitas. Mengenai perihal ini berarti bahwa setiap variabel kepuasan naik maka variabel Beta (Y) juga naik 0,984 berasumsi variabel Independen lainya regresi adalah tidak berubah atau tetap.

\section{Uji F}

Uji $\mathrm{F}$ berguna untuk mengetahui atau memahami pengaruh variabel bebas secara bersama-sama atau simultan terhadap variabel terikat (Pawenang \& Kustiyah, 2011, p. 74-75). Berikut ini hasil uji F dengan menggunakan SPSS yang dapat dilihat pada tabel:

\begin{tabular}{|c|c|c|c|c|c|}
\hline \multicolumn{7}{|c|}{ Tabel 6 Hasil Uji F } \\
\hline Model & Sig. & Std & F hitung & F tabel & Ket \\
\hline Uji F & 0,000 & 0,05 & 56,610 & 0,313 & Hipotesis diterima \\
\hline
\end{tabular}

Sumber data primer 2020

Berdasarkan tabel 6, cara simultan Pelayanan, Citra, Kepuasan terhadap Loyalitas didapat f hitung 56,610; nilai signifikan 0.000; nilai $\mathrm{F}$ hitung 56.610 > F tabel 0.313 dan signifikan $0.000<$ nilai probabilitas 0.05 berarti Ha diterima, artinya secara simultan pelayanan, citra dan kepuasan signifikan mempengaruhi terhadap loyalitas pasien. maka null hipotesis ditolak.

\section{Uji t}

Peneliti menguji hipotesis dan koefisiensi regresi secara statistik atau pengaruh variabel independen terhadap variabel dpenden secara individual (Pawenang \& Kustiyah, 2011, p. 45-49).

Jika Ho diterima $\mathrm{t}$ hitung $>\mathrm{t}$ tabel maka ada pengaruh keduanya. Jika Ho ditolak $\mathrm{t}$ hitung lebih kecil $\mathrm{t}$ tabel berarti tidak ada pengaruh variabel independen terhadap variabel dependen.

Tabel 7 Hasil Uji t

\begin{tabular}{|l|r|l|r|r|l|}
\hline \multicolumn{1}{|c|}{ Variabel } & \multicolumn{1}{c|}{$\mathrm{t}$ hitung } & $\mathrm{t}$ tabel & Signifikan & \multicolumn{1}{c|}{ Std } & Keterangan \\
\hline Pelayanan & -0.131 & 2.11991 & 0.261 & 0.05 & Ditolak \\
\hline Citra & 3.356 & 2.11991 & 0.001 & 0.05 & Diterima \\
\hline Keppuasan & 5.581 & 2.11991 & 0.000 & 0.05 & Diterima \\
\hline
\end{tabular}

Sumber data primer 2020

Berdasarkan data Tabel 7 pengujian dengan SPSS diketahui bahwa:

Pelayanan (X1) terhadap Loyalitas (Y) terlihat nilai signifikan $0.261>0.05$ maka H1 ditolak dan Ho diterima. Nilai t hitung $-1.131<\mathrm{t}$ tabel 2.11991 bahwa variabel Pelayanan tidak mempunyai kontribusi terhadap Loyalitas (Y). Nilai $t$ minus menunjukkan pelayanan mempunyai hubungan berlawanan arah dengan loyalitas. Sehingga Pelayanan tidak mempunyai pengaruh signifikan terhadap Loyalitas. 
Citra (X2) terhadap Loyalitas sig 0,001 $<0.05$ maka H1 diterima dan Ho ditolak. Nilai t hitung $3.356>\mathrm{t}$ tabel 2.11991 bahwa variabel Citra mempunyai kontribusi terhadap loyalitas (Y). Nilai t positif menandakan citra mempunyai hubungan searah dengan loyalitas. Sehingga citra mempunyai pengaruh signifikan terhadap loyalitas.

Kepuasan (X3) terhadap loyalitas (Y) terlihat nilai signifikan $0.000<0.05$ maka H1 diterima dan Ho ditolak. Nilai t hitung 5.581 > t tabel 2.11991 bahwa variabel kepuasan memiliki kontribusi terhadap loyalitas. Nilai t positif menandakan bahwa kepuasan mempunyai pengaruh signifikan terhadap loyalitas.

\section{Koefisiensi Determinasi}

Dalam penelitian ini Nilai Koefisiensi Determinasi di antara nol dan satu, jika $R^{2}=1$ maka variabel independen memberikan info untuk memprediksi variabel dependen sedangkan bila $\mathrm{R}^{2}=0$ maka variabel independen tidak bisa menjelaskan variabel dependen (Pawenang \& Kustiyah, 2011, p. 51).

Tabel 8 hasil Uji Koefisiensi Determinasi

\begin{tabular}{|c|c|c|c|}
\hline Model & R & R Square & Adjusted R square \\
\hline 1 & 0.799 & 0.639 & 0.628 \\
\hline
\end{tabular}

Sumber data primer 2020

Dari data Tabel 8 dengan menggunakan SPSS dapat disimpulkan bahwa Pelayanan, Citra dan Kepuasan berpengaruh sebesar 62,8\% terhadap loyalitas, sedangkan 37,2\% adalah pengaruh lain dari variabel yang tidak diteliti karena nilai $\mathrm{R}$ square mengarah pada nilai nol bahwa kapasitas variabel bebas sangat terbatas.

\section{PEMBAHASAN}

1) Pengaruh secara simultan pelayanan, citra dan kepuasan terhadap loyalitas pasien Klinik Pratama Polres Wonogiri

Berdasarkan hasil pengujian dengan SPSS nilai Fhitung 56,610 > Ftabel 0,313 dengan nilai signifikan lebih kecil dari nilai probabilitas 0,05 maka Hipotesis diterima, berarti variabel pelayanan, citra dan kepuasan secara bersama-sama (simultan) signifikan berpengaruh terhadap loyalitas pasien.

Hasil penelitian ini juga sama atau sesuai dengan penelitian yang dilakukan pada Puspitasari (2017) dan Wijayanti (2008) bahwa loyalitas meningkatkan kepuasan pelanggan dan pelayanan keseluruhan secara signifikan berhubungan positif dengan loyalitas. Persepsi yang baik tentang pelayanan dan citra yang diterima pasien, maka semakin besar harapan pasien akan kepuasan terpenuhi sehingga menimbulkan loyalitas pasien terhadap klinik yang tinggi.

2) Pengaruh pelayanan terhadap loyalitas pasien Klinik Pratama Polres Wonogiri

Berdasarkan hasil pengujian dengan SPSS diketahui nilai thitung $-1,131<\mathrm{t}$ tabel 2,11991 dan hasil signifikan sebesar 0,261 lebih besar dari probabilitas 0,05 maka dapat disimpulkan Variabel Pelayanan tidak berpengaruh signifikan terhadap Loyalitas pasien Klinik Pratama Polres Wonogiri.

Hasil penelitian ini tidak sesuai dengan penelitian yang dilakukan oleh Otani (2010) bahwa pelayanan merupakan hal yang sangat penting untuk menciptakan tercapainya kepuasan dan loyalitas. Hidajahningtyas (2013) bahwa pelayanan memiliki pengaruh positif terhadap kepuasan dan loyalitas yang menimbulkan minat untuk kembali berobat serta merekomendasikan pelayanan rumah sakit pada teman dan keluarga. 
Hasil pelayanan tidak terpengaruh terhadap loyalitas dan tidak terbukti dikarenakan pasien yang terbatas hanya kalangan Polri baik purnawirawan dan keluarganya. Disebabkan juga karena pelayanan yang gratis atau tanpa dipungut biaya sehingga pasien akan kembali berobat ke klinik. Secara real kesan pasien terhadap klinik tetap akan memutuskan untuk berkunjung ulang walaupun dalam pelayananya kurang maksimal dan pasien akan loyal selama apa yang diinginkannya tercapai.

3) Pengaruh citra klinik terhadap loyalitas pasien Klinik Pratama Polres Wonogiri

Berdasarkan hasil pengujian dengan SPSS pada diketahui nilai thitung 3,356 > ttabel 2,11991 dan hasil signifikan sebesar 0,001 lebih besar dari probabilitas 0,05 maka dapat disimpulkan Variabel Citra berpengaruh signifikan terhadap Loyalitas pasien Klinik Pratama Polres Wonogiri.

Hasil penelitian ini sesuai dengan penelitian oleh Darlina (2015) dan Nursaidah (2017) yang menunjukkan bahwa variabel citra berpengaruh positif terhadap loyalitas pelanggan. Citra yang baik akan meningkatkan loyalitas pelanggan sehingga mendorong semangat kerja karyawan, sementara citra yang buruk akan mengakibatkan reputasi klinik akan menurun bahkan memperburuk. Penelitian ini juga sejalan dengan yang diutarakan oleh Wu (2011) bahwa ada fungsi hubungan antara citra merek rumah sakit dengan hubungannya dengan keharmonisan suatu pelanggan yang memiliki efek langsung dan tidak langsung pada loyalitas dan kepuasan.

Citra klinik Pratama Polres Wonogiri akan berdampak pada perilaku dan sikap pasien terhadap loyalitas pasien. Fungsi hubungan antara citra merek klinik dengan hubungannya dengan keharmonisan suatu pelanggan yang memiliki efek langsung dan tidak langsung berdampak pada loyalitas.

4) Pengaruh kepuasan terhadap loyalitas pasien Klinik Pratama Polres Wonogiri

Berdasarkan hasil pengujian dengan SPSS pada diketahui nilai thitung 5,581 > ttabel 2,11991 dan hasil signifikan sebesar 0,000 lebih besar dari probabilitas 0,05 maka dapat disimpulkan Variabel Kepuasan berpengaruh signifikan terhadap Loyalitas pasien Klinik Pratama Polres Wonogiri.

Hasil penelitian ini sesuai dengan penelitian oleh Qomariah (2012) dan Yunida (2016) bahwa kepuasan berpengaruh positif dan signifikan terhadap loyalitas pasien. Kepuasan pasien merupakan bagian yang terpenting dari suatu loyalitas pelanggan. Begitu juga dengan penelitian oleh Meesalaa dan Paul (2018) kepuasan berdampak langsung pada keandalan dan daya tanggap sehingga berkaitan dengan loyalitas pasien.

Kepuasan merupakan fungsi dari persepsi atau kesan atas kinerja dan harapan, pasien merasa puas jika kinerja melebihi harapan pasien, maka mereka akan merasa puas dan senang, kemungkinan besar akan berulang kembali ke klinik tempat awal mulai. Dengan kepuasan berdampak pada banyaknya kunjungan pasien sehingga diharapkan terbentuk kepuasan dan loyalitas. Dengan adanya kepuasan pasien dapat memberikan manfaat terhadap Klinik Pratama Polres Wonogiri sehingga terjadi hubungan yang harmonis antara petugas klinik dengan pasien.

\section{KESIMPULAN}

1) Berdasarkan hasil uji $\mathrm{F}$ bahwa pelayanan, citra dan kepuasan secara simultan berpengaruh signifikan terhadap loyalitas pasien Klinik Pratama Polres Wonogiri.

2) Berdasarkan uji t bahwa:

a. Pelayanan berpengaruh negatif dan tidak signifikan terhadap loyalitas pasien Klinik Pratama Polres Wonogiri. 
b. Citra klinik berpengaruh signifikan dan positif terhadap loyalitas pasien klinik Pratama polres Wonogiri.

c. Kepuasan berpengaruh signifikan dan positif terhadap loyalitas pasien klinik Pratama polres Wonogiri.

3) Berdasarkan uji Regresi linear berganda menunjukkan bahwa:

a. Setiap kenaikan pelayanan terhadap variabel Beta (Y) 0,129 bahwa variabel independen yang lain tidak berubah atau tetap.

b. Setiap kenaikan citra terhadap variabel beta (Y) 0.379 bahwa variabel independen yang lain tidak berubah atau tetap.

c. Setiap kenaikan kepuasan terhadap varibael beta (Y) 0.984 bahwa variabel independen yang lain tidak berubah atau tetap.

4) Berdasarkan uji koefisien determinasi bahwa Pelayanan, Citra dan Kepuasan berpengaruh sebesar $62,8 \%$ terhadap loyalitas, sedangkan 37,2\% dipengaruhi varibel diluar penelitian.

\section{SARAN}

1) Klinik Pratama agar meningkatkan pelayanan dan memprioritaskan pelayanan yang cepat, tepat, akurat dan mempertahankan citra klinik yang diharapkan oleh pasien untuk meningkatkan loyalitas pasien.

2) Klinik Pratama Polres Wonogiri agar menyediakan kotak saran dan kritik untuk mengetahui keluhan, keinginan, dan harapan pasien sebagai bahan masukan dengan tujuan untuk menigkatkan pelayanan kesehatan.

3) Tenaga kesehatan diharapkan lebih tepat waktu melayani atau menangani pasien sehingga dengan efektifitas waktu pelayanan merupakan penentu kepuasan dan loyalitas pasien.

4) Klinik agar memperhatikan dan menyediakan tempat parkir tersendiri khusus untuk pasien sehingga memudahkan untuk dijangkau pasien.

5) Klinik Pratama Polres Wonogiri agar meningkatkan fasilitas non medis dengan cara menambah pendingin ruangan, menambah tempat duduk tunggu pasien sehingga kenyamanan pasien terjaga.

\section{DAFTAR PUSTAKA}

Abdurrouf, M., Puspitasari, D. W. (2017). Model Loyalitas Pasien Berbasis Kualitas Pelayanan Rumah Sakit Islam Di Semarang. Jurnal Kesehatan, Vol. 8 (3), p. 435-440

Arikunto, Suharsimi. (2006). Prosedur Penelitian Suatu Pendekatan Praktik. Jakarta: Rineka Cipta

Daryanto \& Ismanto Setyabudi. (2014). Konsumen dan pelayanan prima. Yogyakarta: Gava Media

Ghozali, I. (2013). Aplikasi analisis multivariate dengan program ibm dan spss 21 update pls regresi, Edisi 7. Badan Penerbit Universitas Diponegoro

Hidajahningtyas, Nurullah. (2013). Pengaruh citra poliklinik eksekutif rumah sakit daerah dr. Soebandi kabupaten jember. Jurnal Manajemen Bisnis Indonesia (JMBI). Vol. 12 (1).

Hurriyati, Ratih. (2005). Bauran pemasaran dan loyalitas konsumen. Bandung: Alfabeta 
Kotler, P. (2002). Manajemen pemasaran. (terjemahan). In Edisi Millenium, Jilid 1. Jakarta (ID): Prenhallindo

Kotler, Philip. (2007). Manajemen pemasaran. Edisi Kedua belas, Jilid 2 Edisi Bahasa Indonesia. Jakarta (ID): Indeks Gramedia

Ma'ruf, M. H. (2016). Analisis Pengaruh Kualitas Pelayanan Terhadap Kepuasan Pasien Pada Rumah Sakit Umum Daerah Sukoharjo. Jurnal Akuntansi dan Pajak, 16(02).

Mukti, Ali Ghufron. (2007). Strategi terkini peningkatan mutu pelayanan kesehatan: konsep implementasi. Yogyakarta: PT. Karya Husada Mukti.

Muninjaya, A. A. Gde. (2004). Manajemen Kesehatan. Edisi 2. Jakarta: EGC

Nursaidah. (2017). Pengaruh citra produk terhadap loyalitas nasabah dengan kepuasan nasabah sebagai variabel intervening pada pt. Bank Rakyat Indonesia (persero), tbk. Cabang jember. Jurnal Manajemen Dan Bisnis Indonesia. Vol. 3(2), p. 218-238

Otani, K., Herrmann, P. A., \& Kurz, R. S. (2010). Improving patient evaluation of hospital care and increasing their intention to recommend: are they the same or different constructs? Health Services Management Research. Vol. 23 (2), p. 60-65.

Paul, J. Peter dan Jerry C. Olson. (2000). Consumer behavior: perilaku konsumen dan strategi pemasaran. Terjemahan. Jakarta (ID): Erlangga

Pawenang, S, \& Eny Kustiyah. (2011). Pengantar ekonometrika. Yogyakarta: Idea Pres.

Pohan, I. (2006). Jaminan mutu layanan kesehatan dasar dasar pengertian dan penerapan. Jakarta: EGC. Buku Kedokteran

Pohan, Imbalo S. (2006). Jaminan mutu pelayanan kesehatan, dasar-dasar pengertian. Jakarta: Kesaint Blanc

Qomariah, Nurul. (2012). Pengaruh kualitas layanan dan citra institusi terhadap kepuasan dan loyalitas pelanggan. Jurnal Aplikasi Manajemen. Vol. 10. No. 1

Satianegara, M. F. dan S. S. (2009). Buku ajar organisasi dan manajemen pelayanan kesehatan serta kebidanan. Jakarta: In Salemba Medika (1st ed.)

Sutisna. (2001). Perilaku konsumen dan komunikasi pemasaran. Bandung: Remaja Rosdakarya

Wu, C. (2011). The impact of hospital brand image on servive quality, patient satisfaction and loyalty. Journal of Business Management. Vol. 5(12), pp. 4873-4882. 